\title{
Designing for Denial: Private Property on Dauphin Island
}

\author{
MAGGIE TSANG \\ Harvard Graduate School of Design
}

\author{
ISAAC STEIN \\ Harvard Graduate School of Design
}

Rather than escalate the concept of "climate change" into a massive, intractable problem with a passionate cadre of worried supporters, this paper advances the concept that growing engagement and knowledge around environmental change should be made personal and political through sitespecific protocols. Using the case study of Dauphin Island, Alabama; this paper examines latent spatial potential of private property along coastal landscapes that are facing sea level rise, increasing storm events, and shoreline erosion. On this barrier island, resilience is a term that applies more to real estate than to the island's ecology; despite the visibly changing landscape, new development, investment, and reconstruction efforts continue at the water's edge. Here, conflicts between property interests and shoreline dynamics generate a landscape of contradictions, but simultaneously open the door for alternative sites and strategies of engagement and activism. Ultimately, we argue that designers can forgo the uphill battle for legislative change, political realignment, and economic restructuring; and instead leverage physical space and the embedded spatial logics of development to reveal the shortcomings of the status quo and to encourage alternative attitudes towards land and the changing climate.

For as the shore configuration changes in the flow of time, the pattern of life changes, never static, never quite the same from year to year. Whenever the sea builds a new coast, waves of living creatures surge against it, seeking a foothold, establishing their colonies. And so we come to perceive life as a force as tangible as any of the physical realities of the sea, a force strong and purposeful, as incapable of being crushed or diverted from its ends as the rising tide. ${ }^{1}$

\section{INTRODUCTION}

Consider the moon-an otherworldly presence whose magnitude and influence are nearly impossible to perceive. Only after several hours on the beach, when the tide laps forward to wet your towel might the moon make its presence known. Likewise, the immense scale of planetary change is not easily comprehended. In fact, the concept of a changing climate frequently induces cognitive paralysis, clouds political agency, and stifles creative approaches to pressing problems. While short-term "natural disasters"2 are easier to respond to; longer-term, cyclical forms of environmental change are more troublesome. Climate change, as a term of art, tends to be as thin as the atmosphere it depicts; an amorphous concept that is hard to grasp. In this vacuum, "everyday denial" becomes an easy practice of nonresponse, not as an expression of ignorance or lack of concern, but rather as a result of a distance from reality. ${ }^{3}$ The design disciplines, however, are uniquely suited to address the psycho-spatial dissonance that largescale environmental degradation puts forth. By critically engaging site- and scale-specific strategies; architects, landscape architects, and planners can mediate the multi-faceted complexities of environmental change.

Recall your wet beach towel-your intimate connection to the moon through tidal movement. This is the scale at which individuals, communities, and institutions realize their agency in the environment. Do you move your beach towel to avoid high tide? Or do you stay and get soaked? The media and methods with which one represents these questions matters. Thus, rather than escalate the concept of "climate change" into a massive, intractable problem with a passionate cadre of worried supporters, this paper advances the concept that growing engagement and knowledge around environmental change should be made personal and political through sitespecific protocols.

This paper uses the case study of Dauphin Island, Alabama to demonstrate how scale, site, and strategy create new opportunities for design activism. Specifically, we focus on the impact of private property along barrier islands, which are prone to increasing storm events, sea level rise, and shoreline erosion. In this region, private property reigns supreme; and despite the visibly changing landscape, development continues at the water's edge. Here, conflicts between property interests and shoreline dynamics generate a landscape of contradictions, but simultaneously open the door for alternative sites and strategies of engagement and activism.

\section{THE CASE OF DAUPHIN ISLAND}

Along thousands of miles of the eastern seaboard of the United States, private property fortifies the edge of the coastline like crenellated ramparts. It is estimated that approximately 23 million people live within six meters of the mean high tide line; and the residences of 3.7 million people would be inundated if sea levels rise one meter. ${ }^{4}$ Barrier islands, which protect the mainland coasts of the eastern seaboard, represent the physical frontlines of this environmental phenomenon. While this impact demands a radical restructuring of the built environment, the political and economic institutions that support development on these islands have proven anathema to 


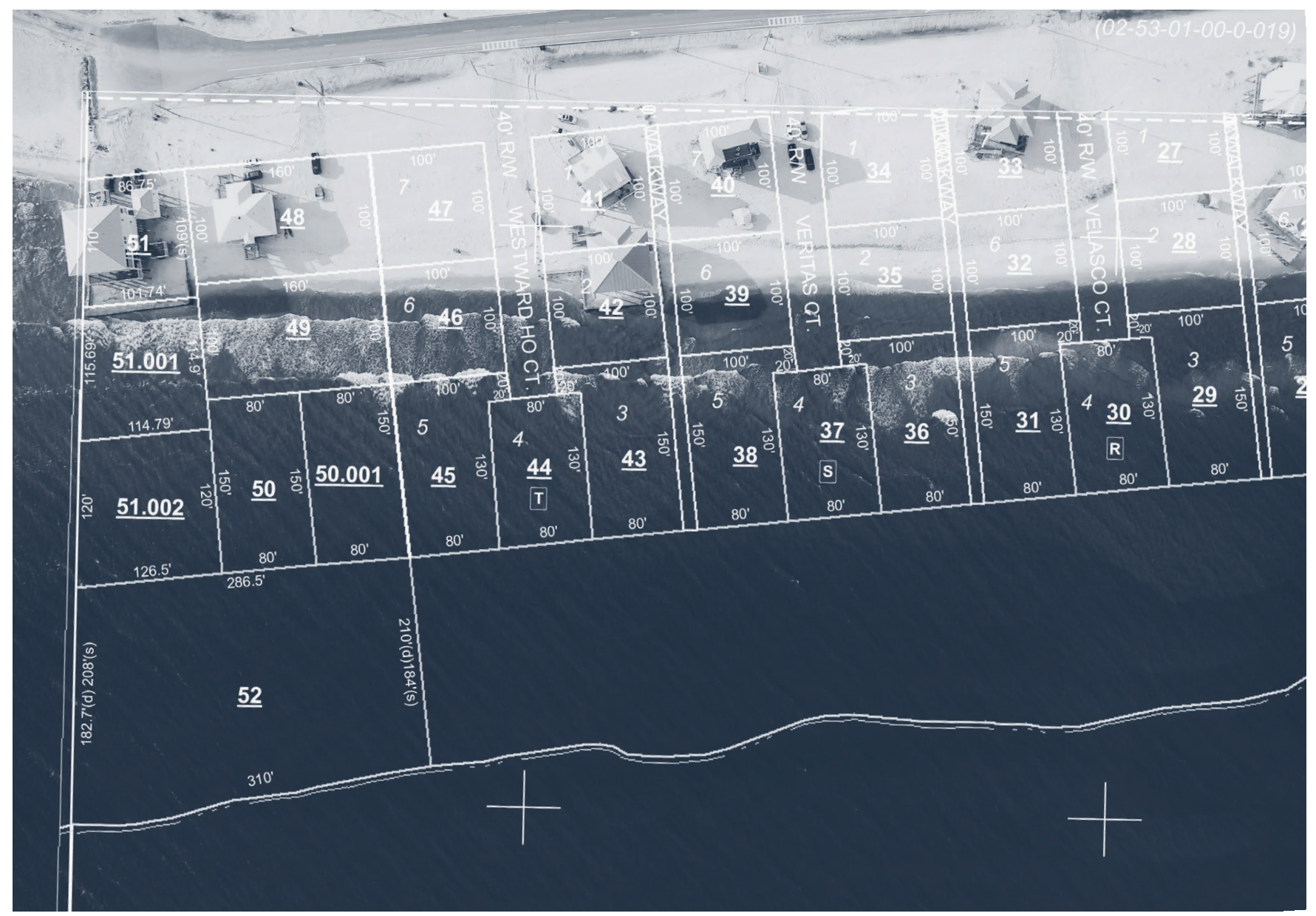

Figure 1. Plat of Dauphin Island West Surf Beach Subdivision and 2018 Aerial.

change. This is nowhere more evident than on Dauphin Island, Alabama. At present, there are at least sixty parcels on the West End of Dauphin Island that are fully submerged and now extend out into the Gulf of Mexico (figure 1). State law recognizes submerged land as public, and yet the lots are considered private property by owners who continue to pay property taxes and mortgages. Ultimately, no one has claimed responsibility over this space as state authorities avoid confrontation with owners and owners clutch onto their property rights.

Though local governments understand the environmental dynamics in this region, they have resisted discussions of adaptation or retreat. Instead, their economic dependency on real estate and their cultural preference for private homeownership have led to land use policies that protect, maintain, and defend the status quo. A Mobile County official and Dauphin Island local, stated, "I don't see the island ever being allowed to erode away. I see property protection being front and center on the island, forever."5 Ultimately, submerged property on Dauphin Island demonstrates how the invisible lines that define ownership determine the physical environment and alter conventional legal approaches to sea level rise and land loss.

\section{THE RESILIENCE OF PROPERTY}

Dauphin Island is a product of sedimentary deposits from the ebb-tidal delta of Mobile Bay, the fourth largest estuary in the country. Within geologic timescales, this land is young having only been formed in the last 10,000 years, and as such, is extremely mobile and unstable. In general, barrier islands are a product of sea level rise from the previous ice age and are geomorphologically predisposed to migrate landward through a process of sediment transfer. On the West End of Dauphin Island, this dynamic is visible: the shape of the island changes radically from year to year, frequently eroding and accreting land mass. A comparative study of satellite imagery shows that the shoreline is constantly in flux and the island is generally winnowing (figure 2).

As a result of this extreme dynamism, on the West End of Dauphin Island, there are currently sixty or more submerged parcels that are retained as private property. As of 2018, the Mobile County Revenue Commission still collects their property tax. Lots that are completely submerged are typically appraised at $\$ 1,000$ and the owner pays approximately \$10 tax annually. "I pay more than that on lunch sometimes," said Greg Eastburn Jr., an appraiser at the 


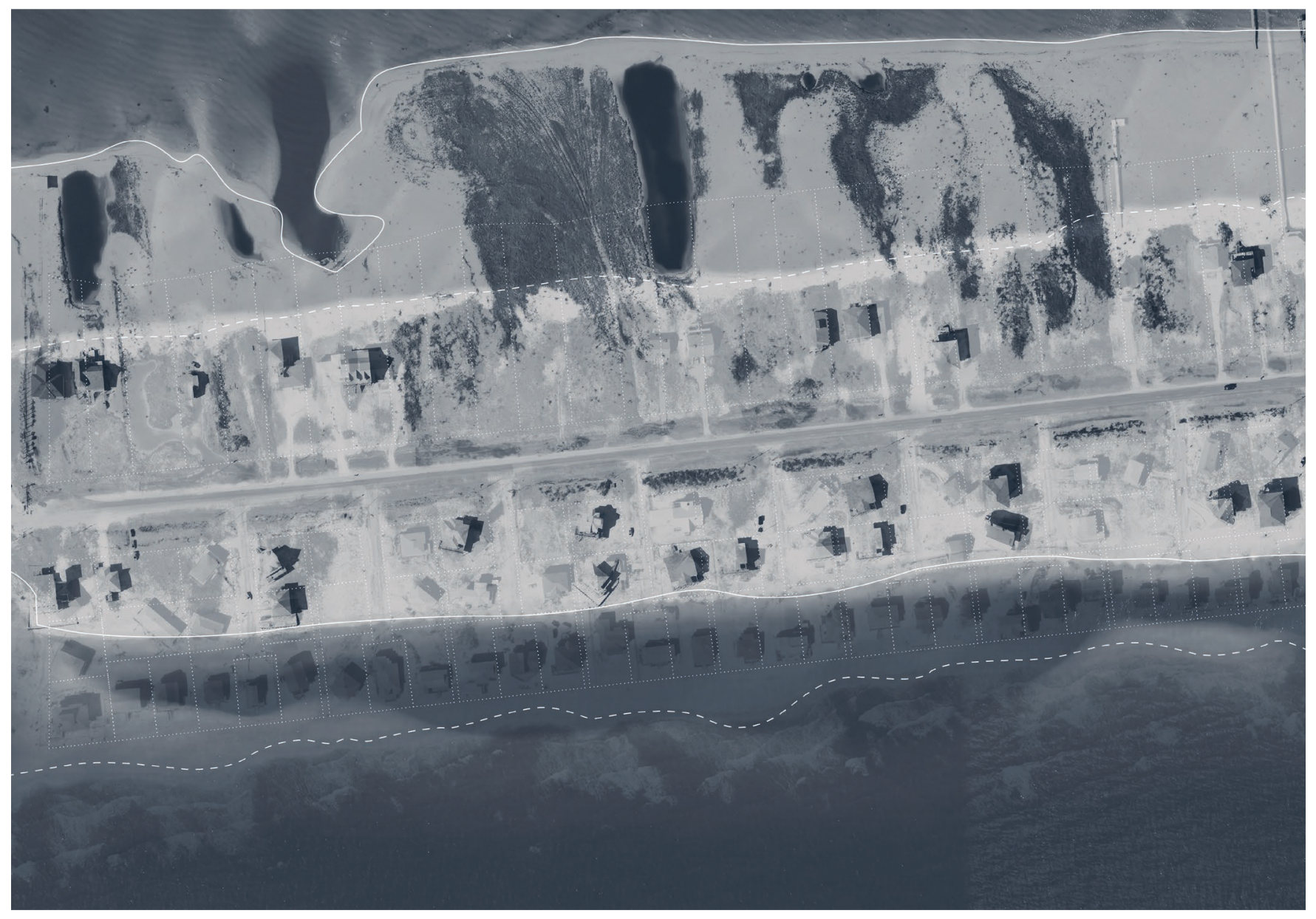

Figure 2. Dauphin Island West Surf Beach Subdivision at 1997 and 2014.

Mobile County Revenue Commission. "We can't just put a zero value on it, even if it's underwater. So there will always be some sort of nominal value." ${ }^{6}$ Even in the absence of ground, parcel lines continue to define ownership and assets. Furthermore, in 1988 Mobile County drew a Coastal Construction Control Line (CCCL), which was intended to mark a protected zone between development and the shoreline. Today, the line lies 450 feet offshore in the Gulf of Mexico and has not been redrawn (figure 3). Thus by law, the submerged parcels "landward" of the CCCL are technically still developable.

Whereas coastal municipalities have readily co-opted the word "resilience" in their rhetoric to signify a commitment to environmental planning, ${ }^{7}$ closer examination of this term reveals an underlying economic and political agenda. "Resilience" originates from the literature of ecology and specifically describes "the capacity of an ecological system to undergo disturbance and maintain its functions and controls...resilience is measured by the magnitude of disturbance the system can tolerate and still persist.." ${ }^{18}$ But, when used by local government and developers, "resilience" is grafted onto exclusively human systems, ${ }^{9}$ and indicates not the capacity of an island's ecology to survive disturbance, but rather the capacity of real estate to persist in its function of extracting economic value from space-the resilience of property.

On Dauphin Island, property is very resilient. Each successive storm has driven down property values: the island lost 150 homes in Hurricane Ivan and 350 homes the following year in Hurricane Katrina. But each time the National Flood Insurance Program has subsidized recovery and encouraged rebuilding houses in the exact same locations. Whereas the instability of the land would suggest the necessity to cede ground and retreat from the shoreline, political and economic interests in private real estate forces the municipality into a defensive position. After every washout, the town exploits taxpayer dollars to reconstruct infrastructure-roads, power, water, and sewer lines-in predictably vulnerable areas of the island. Therefore, county, state, and municipality subsidize the maintenance and rebuilding of private residences on the shoreline. Furthermore, on the west end of Dauphin Island, as with many barrier islands of the Eastern Seaboard, vacation and second homes comprise a majority of the building 


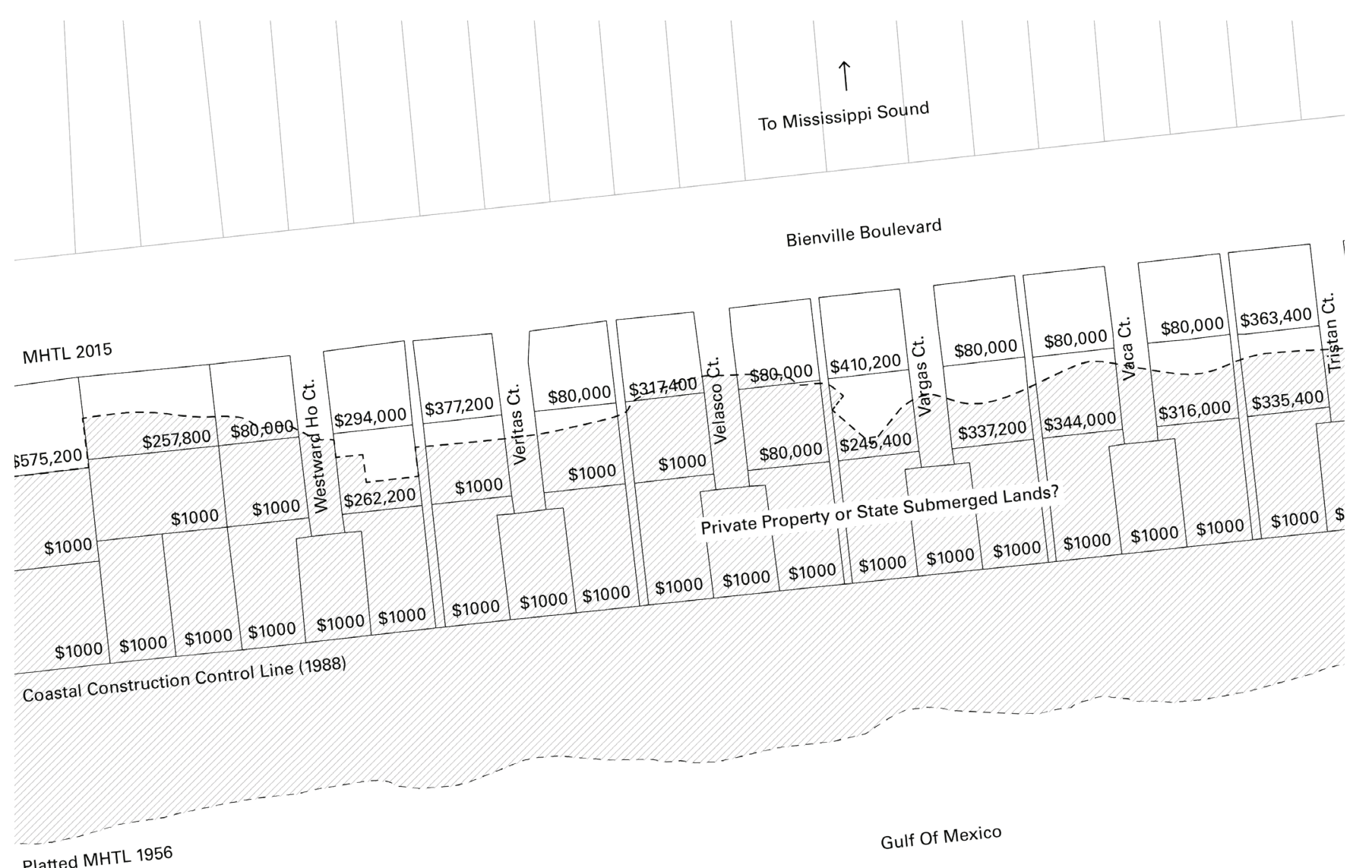

Platted MHTL 1956

Figure 3. Plan of Submerged Parcels, Mean High Tide Line (MHTL), and CCCL in Dauphin Island West Surf Beach Subdivision.

stock. Ultimately, Dauphin Island's redevelopment regime reveals how resilience operates to preserve private property first and foremost, and the reluctance to alter land use policies reproduces a landscape of risk that is ultimately carried on the shoulders of the public.

\section{PRODUCTIVE LEGAL AMBIGUITY}

The case of Dauphin Island, and other barrier islands on the eastern seaboard, demonstrates how environmental impacts on dynamic landforms can become arenas for law-making. In the United States, property that falls below the Mean High Water Line is considered state lands and held in trust for the public. This common law, known as the Public Trust Doctrine, was formally established by the US Supreme Court in their ruling of Illinois Central Railroad Co. v. Illinois: "It is the settled law of this country that the ownership of and dominion and sovereignty over lands covered by tide waters, within the limits of several states, belong to the respective states within which they are found, with the consequent right to use of dispose of any portion thereof, when that can be done without substantial impairment of the interest of the public in the waters..."10 But despite this precedent, the approach to sea level rise has been piecemeal and inconsistent.
On Dauphin Island the public trust doctrine has not been enforced and submerged private property remains prevalent. Alabama law states that any sudden, dramatic loss of land, known as an avulsion, requires the state to compensate property owners. The gradual, slow loss of land, or erosion, does not. ${ }^{11}$ Warming waters and sea level rise however alter the impact of these phenomena, respectively. Two questions arise: First, will the state continue to compensate property owners that maintain properties in areas prone to increasing avulsive events? Second, with the increasing rate of sea level rise and erosion, will private property owners claim a takings? On this subject, legal scholar J. Peter Byrne writes: "insofar as the Supreme Court's conservative majority has pursued an ideal of essential, or natural, property rights unchangeable without compensation, the dynamic physical transformations promised by sea-level rise show the need for a more lenient and flexible constitutional approach recognizing that property rules do and must evolve in accord with social and ecological change." 12 The difficulty of constitutional change and the reluctance of states and property owners in the interim allows for the maintenance of the status quo and invites a productive ambiguity. 


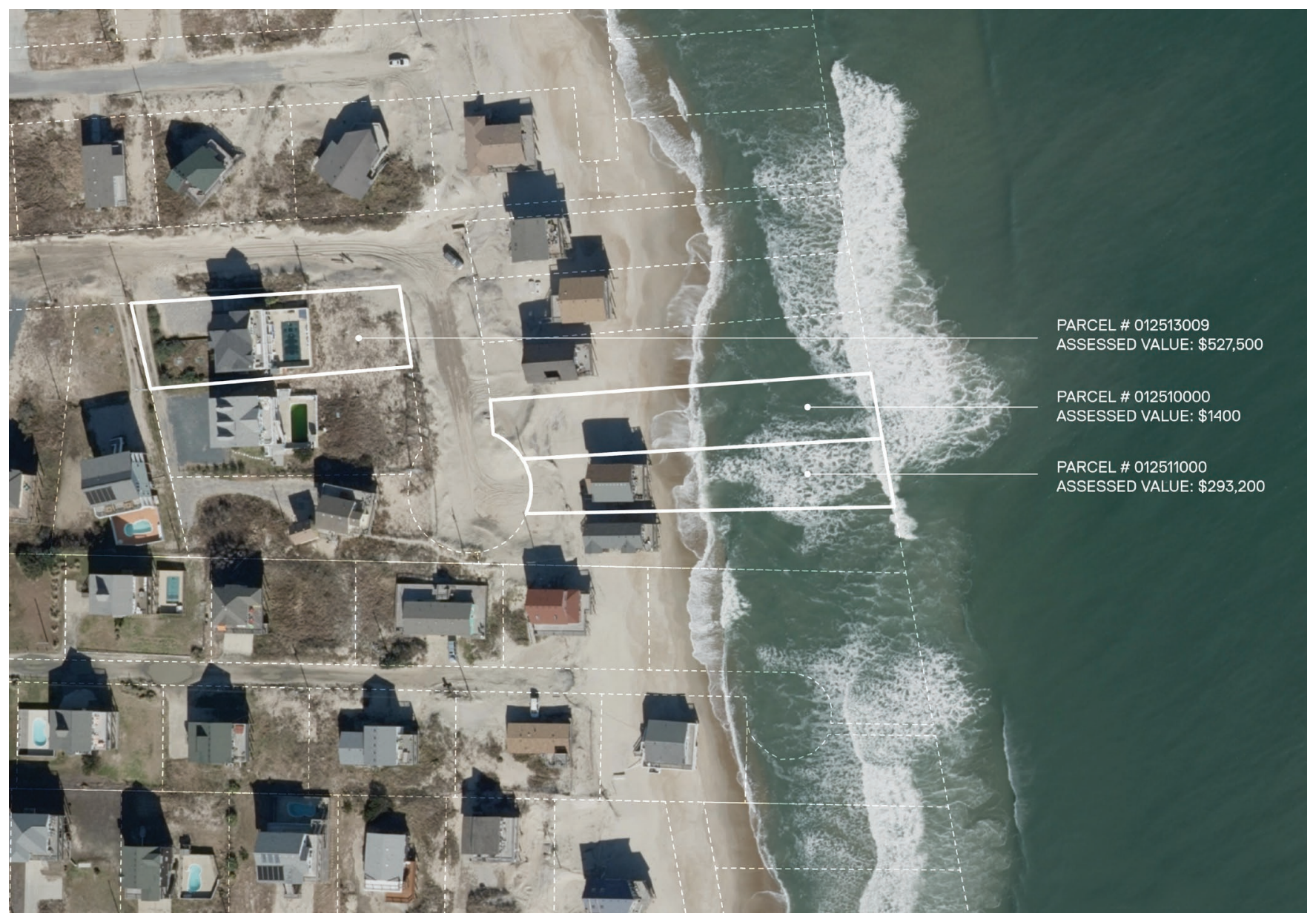

Figure 4. Property Assessment of Coastal Parcels.

In lieu of broad legislation or judicial decisions, lawmakers in coastal states have turned towards other avenues of regulation for sea level rise. In North Carolina, for example, the state passed a law limiting the adoption of sea level rise projections on land use regulations. Fearing the threat of decreased economic activity in coastal municipalities, the state sought to unbar development in vulnerable areas and ignore the apparent risks. ${ }^{13}$ In contrast, New Jersey initiated a program called "Blue Acres" which funds voluntary property acquisitions in floodplains and flood prone areas and converts private property to public conservation and recreation areas. ${ }^{14} \mathrm{Up}$ and down the coast, there are a gradient of approaches, but these disparate responses form a patchy set of regulations.

\section{OLD LOGICS: BUY-A-LOT}

The denial of policy makers and economists has affected physical space by unwittingly condemning the built environment into costly cycles of destruction and reconstruction. Rather than join the uphill battle for legislative change, political realignment, and economic restructuring; however, architects, landscape architects, and designers can instead leverage physical space to undermine and subvert development logics. As Keller Easterling suggests: "There are times to stand up, name an opponent, or assume a binary stance of resistance against authoritarian power, but supplementing these forms of dissent are activist stances that are both harder to target and less interested in being right." ${ }^{\prime 15}$ To keep pace with rapid environmental degradation, spatial practices and design disciplines cannot continue to be limited to their role in projecting visions of an ideal future for the coast or proposing large-scale infrastructural solutions. Rather, the designer's imperative should be to "stay with the trouble"16 and to tune into the institutional and spatial contradictions that already exist in specific locales. Working within current rules, regulations, and patterns of development; rather than against them, can do more to unravel logics and instigate action and civil engagement.

One such example of this type of design work is Buy-A-Lot, a landscape initiative that aggregates vacant or washed out land on barrier islands to prevent development in areas of chronic environmental risk (figure 4). The organization models alternative mechanisms for the purchase and aggregation of liminal lots and mimics the activities of a land trust. Unlike the conservation land trust, however, Buy-A-Lot is not motivated by the preservation of an assumed nature or untouched landscape. Rather, conspiring with the particular 
dynamics of sediment transfer and wave action, Buy-A-Lot uses landscape strategies to amass property and accelerate the landward migration of barrier islands. Ultimately, this creates a spatial ultimatum for homeowners on the water's edge: maintain their property through engineering efforts at cost or cede their property to erosion. By sparking this kind of decision-making, Buy-A-Lot encourages preemptive retreat and aims to reduce the public's burden in subsidizing services for privatized shorelines.

Initiatives that leverage existing rules, regulations, and cultural preferences as they manifest in physical space demonstrate that the design disciplines are not simply engaged in the act development, subject to the demands of the real estate market, but rather agents capable of shaping the process of change: not only growth and building, but also shrinkage and unbuilding. This requires the spatial acuity that designers embody as well as a pragmatic willingness to work within the social and cultural logics of a given locale. For Buy-A-Lot, this means tuning into the primacy of private property and the real estate market as well as the geomorphological and environmental forces that oppose it. This type of work lives on the fringes of social art practice, real estate development, landscape architecture, and land use planning. Not unlike Gordon Matta-Clark's "Reality Properties: Fake Estates"17 and Amy Balkin's "Public Domain"18 and "Land: Land: Five Four Case Studies," ${ }^{19}$ critical design activism around environmental issues examines the social, legal, and economic potential of precarious land and places at risk. While both Matta-Clark and Balkin make the simple point that property is funny, they fail to move beyond the critique and their work remains isolated and singular. For critical design activism to address issues of environmental degradation and climate, spatial protocols need to be designed to unfold over time and to accommodate the real institutional, financial, and social drivers that have a stake in the process and outcomes.

\section{CONCLUSION}

If typical approaches to environmental policy come primarily from two directions - top-down from the state, or bottom up, led by grassroots movements and activists-then this paper charts an alternative path, one that engages and challenges spatial practice. While planners and designers have typically been hired and consulted to determine the physical look and feel of a future affected by sea level rise, they have not been engaged in the latent issues of property and land use. Through our study of private property's unyielding grasp on Dauphin Island's landscape and built environment, we have sought to demonstrate the design potential of the invisible forces of ownership and the logics of development. Historically, if these forces have created the hardened physical environments of barrier islands, then they can also be harnessed to unravel them. Planetary environmental degradation has no panacea, but rather requires attention to specific sites and scales of intervention. Departing from the traditional design approaches invites serious consideration about ethics, expertise, intent, and responsibility. Regardless, architecture and landscape are both deeply implicated in the changes of environment, and yet designers have not yet realized their influence and capacity to shapes sites, rescript development logics, and devise spatial strategies that will give context and space to an otherwise monstrous planetary dilemma, and will ultimately instigate action and engagement rather than denial and inertia.

\section{ENDNOTES}

1 Rachel Carson, The Edge of the Sea (Boston, MA: Houghton Mifflin Company, 1955), 250.

2 Neil Smith, "There's No Such Thing as a Natural Disaster," Understanding Katrina: Perspectives from the Social Sciences, June 11, 2006. http://understandingkatrina.ssrc.org/Smith/.

3 Kari Marie Norgaard, Living in Denial (Cambridge, MA: The MIT Press, 2011).

4 Benjamin H. Strauss et al., "Tidally Adjusted Estimates of Topographic Vulnerability to Sea Level Rise and Flooding for the Contiguous United States," Environmental Research Letters 7 (2012). http://iopscience.iop.org/17489326/7/1/014033/pdf/1748-9326_7_1_014033.pdf.

5 Anonymous, Mobile County, Interview with Author, July 11, 2018.

6 Greg Eastburn, Interview with Author, July 9, 2018.

7 Rebuild by Design states: “Our cities were built in response to yesterday's problems. As the world faces rising populations, climate change, and economic challenges, communities can't afford to wait until after the next hurricane or flood, or ignore chronic stresses such as aging infrastructure and pollution, to plan for the future. Rebuild By Design is reimagining the way communities find solutions for today's large-scale, complex problems...Rebuild by Design uses collaborative, design-driven problem-solving to help communities and cities build resilience." Rebuild by Design "About" page, Rebuild by Design official website, http://www.rebuildbydesign.org/about.

8 C.S. Holling, "Resilience and the Stability of Ecological Systems," Annual Review of Ecology and Systematics 4 (1973): 1-23.

9 Steve Carpenter et al., "From Metaphor to Measurement: Resilience of What to What?" Ecosystems 4 (2001): 765-781.

10 Illinois Central Railroad Co. v. Illinois 146 US 387, 435 (1892).

11 Ala Code § 220-4-09; Ala. Code § 33-7-50 (1975).

12 Peter Byrne, "The Cathedral Engulfed: Sea-Level Rise, Property Rights, and Time," Louisiana Law Review 73 (2012): 69-118.

13 General Assembly of North Carolina, Senate Agriculture/Environment/ Natural Resources Committee, House Bill 819: Coastal Management Policies, Session 2011.

14 "Blue Acres Floodplain Acquisitions," State of New Jersey Department of Environmental Protection official website, accessed July 24, 2018. https://www. nj.gov/dep/greenacres/blue_flood_ac.html.

15 Keller Easterling, Extrastatecraft: The Power of Infrastructure Space (London: Verso, 2014).

16 Donna Jeanne Harraway, Staying with the Trouble: Making Kin in the Chthulucene (Durham: Duke University Press, 2016).

17 Gordon Matta-Clark, “Reality Properties: Fake Estates," artwork (1973).

18 Amy Balkin, This is the Public Domain official website, 2003. http://www.thisisthepublicdomain.org/.

19 Amy Balkin, "Land: Five Four Case Studies (Dawson, YK, Huntington Beach, CA, Newark, CA, Tres Piedras, NM, Richmond, TX)," project, 2010. http://tomorrowmorning.net/landcasestudies. 